\title{
DE OLHO NO CÉU: DIVULGAÇÃO CIENTÍFICA PARA COM AS CRIANÇAS EM ESPAÇO NÃO FORMAL MANAUARA
}

\section{WITH EYES IN THE SKY: SCIENTIFIC DISCLOSURE FOR CHILDREN IN NON- FORMAL SPACE}

\section{EN EL CIELO: DIVULGACIÓN CIENTÍFICA PARA NIÑOS EM ESPACIO NO FORMAL}

\author{
Alexandra Nascimento de Andrade* (i) ( \\ Adana Teixeira Gonzaga *** (D) \\ Carolina Brandão Gonçalves *** (D) 9
}

\begin{abstract}
RESUMO
Este artigo aborda uma experiência - Exposição De olho no céu - realizada no Largo São Sebastião, Manaus - AM, em parceria com o Museu Amazônico, órgão suplementar da Universidade Federal do Amazonas (UFAM). A atividade teve como objetivo analisar o interesse das crianças por temas de Astronomia, identificando seus conhecimentos prévios e curiosidades sobre as temáticas que envolvem os corpos celestes, salientando assim, a importância dos museus para a democratização da ciência, desde o público infantil. $\mathrm{O}$ artigo possui uma abordagem qualitativa, com enfoque descritivo. A técnica de gerenciamento de dados foi a observação participante, mediante a gravações, filmagens e fotografias, por meio de smartphones. Diante da Análise de Conteúdo, elencou-se cinco categorias: 1) curiosidades; 2) reações; 3) desejo de conhecer os corpos celestes; 4) conhecimento apresentado; e, 5) A importância de atividades de democratização à ciência em espaços não formais. De acordo com os resultados, as crianças demonstraram interesse em participar das atividades, dialogando entre si e com as pesquisadoras, respondendo perguntas sobre os planetas e aprendendo algumas curiosidades (tamanho dos planetas do sistema solar, quantos planetas tem anéis, outros). O estudo possibilitou mostrar uma prática de divulgação científica realizada em um espaço não formal, com crianças de várias nacionalidades, idades e classes sociais, demonstrando a necessidade de mais práticas que envolvam temáticas científicas para esse público na cidade de Manaus - AM.
\end{abstract}

Palavras-chave: Crianças. Astronomia. Divulgação Científica. Democratização da Ciência. Espaço não formal.

\section{ABSTRACT}

This article discusses an experience - Exhibition With an Eye on the Sky - held at Largo São Sebastião, Manaus - AM, in partnership with the Amazon Museum, a supplementary organ of the

\footnotetext{
* Mestre em Educação em Ciências na Amazônia pela Universidade do Estado do Amazonas (UEA). Pedagoga (Seduc - Am), Manaus, Amazonas, Brasil. Endereço para correspondência: Rua Argonalta, 252, Distrito Industrial 2, Manaus, Amazonas, Brasil, CEP: 69007-057. E-mail: alexandra_deandrade@ @otmail.com.

** Mestra em Educação em Ciências na Amazônia pela Universidade do Estado do Amazonas (UEA). Manaus, Amazonas, Brasil. Endereço para correspondência: Rua Mutum do Norte, n.35, Tarumã Açu, Manaus, Amazonas, Brasil, CEP: 69023-097. E-mail: adanatg05@gmail.com.

*** Doutora em Ciências da Educação pela Universidade do Minho (2010), Braga - Portugal. Professora do Programa de Pós-graduação em Educação e Ensino de Ciências na Amazônia (UEA), Manaus, Amazonas, Brasil. Endereço para correspondência: Avenida Joaquim Nabuco, n. 1572, Centro. Manaus, Amazonas, Brasil, CEP: 69.005-080. E-mail: cbgoncalves@uea.edu.br
} 
Federal University of Amazonas (UFAM), which aimed to analyze the interest of children in Astronomy themes, identifying their previous knowledge and curiosities about the themes involving celestial bodies, thus highlighting the importance of museums for the democratization of science, from the child audience. The article has a qualitative approach, with a descriptive focus. The data management technique was participant observation, through recordings, footage and photographs, through smartphones, which helped us to list in five categories: 1) curiosities; 2) reactions; 3) desire to know the celestial bodies; 4) knowledge presented; and, 5) The importance of democratizing science activities in non-formal spaces. According to the results, the children showed interest in participating in the activities, talking to each other and to the researchers, answering questions about the planets and learning some curiosities (size of the planets in the solar system, how many planets have rings, others). The study made it possible to show a practice of scientific dissemination carried out in a non-formal space with children of various nationalities, ages and social classes, demonstrating the need for more practices involving scientific themes for this audience.

Keywords: Kids. Astronomy. Scientific divulgation. Democratization of Science. Non-formal space.

\section{RESUMEN}

Este artículo analiza un experimento - Exposición con la mirada en el cielo - realizado en Largo São Sebastião, Manaus - AM, en asociación con el Museo Amazonas, un órgano complementario de la Universidad Federal de Amazonas (UFAM), que tuvo como objetivo analizar el interés de niños en temas de Astronomía, identificando sus conocimientos previos y curiosidades sobre los temas relacionados con los cuerpos celestes, enfatizando así la importancia de los museos para la democratización de la ciencia, desde el público infantil. El artículo tiene un enfoque cualitativo, con enfoque descriptivo. La técnica de manejo de datos fue la observación participante, a través de grabaciones, metraje y fotografías, utilizando teléfonos inteligentes que nos ayudaron a enumerar en cinco categorías: 1) curiosidades; 2) reacciones; 3) deseo de conocer los cuerpos celestes; 4) conocimiento presentado; y, 5) La importancia de democratizar las actividades científicas en espacios no formales. Según los resultados, los niños mostraron interés en participar en las actividades, hablar entre ellos y con los investigadores, responder preguntas sobre los planetas y conocer algunas curiosidades (tamaño de los planetas en el sistema solar, cuántos planetas tienen anillos, otros ). El estudio permitió mostrar una práctica de divulgación científica realizada en un espacio no formal con niños de diversas nacionalidades, edades y clases sociales, demostrando la necesidad de más prácticas de temática científica para este público.

Palabras clave: Niños. Astronomía. Divulgación científica. Democratización de la ciencia. Espacio no formal.

\section{INTRODUÇÃO}

Assuntos relacionados à Astronomia são de grande encantamento no universo infantil, corroborando com a pesquisa de Andrade (2018; 2020) que parte da perspectiva da abordagem de experiências que tem os fenômenos observáveis pelas crianças como princípio de potencialidade para o ensino com elas, como por exemplo: as curiosidades de descobrir/ explorar - planetas, estrelas, extraterrestres entre outros, sendo de suma relevância para as suas interrelações com o meio ambiente em que habita. 
Nesse contexto, refletir em propostas que mobilizem um pensar científico, possibilita a construção de pesquisas e atividades científicas que envolvem crianças e Astronomia como uma discussão emergente na cidade de Manaus - AM. Por isso, entende-se que a Divulgação Científica (DC) é o caminho para que ocorra a aprendizagem de conceitos sobre essa área do conhecimento desde a mais tenra idade, já que um dos objetivos da DC é tornar o conhecimento científico acessível para os diversos públicos.

As perspectivas da divulgação científica associadas à utilização de espaços não formais podem tornar a aprendizagem muito mais significativa para crianças, pois, elas entram em contato com o ambiente e começam a olhar esse espaço com "outros olhos", além de adquirir informações científicas, mediante atividades lúdicas e informais.

Nesse contexto, visa-se, nesta investigação, analisar o interesse das crianças por temas de Astronomia, identificando seus conhecimentos prévios e curiosidades sobre as temáticas que envolvem os corpos celestes, salientando a relevância dos museus para a democratização da ciência, desde o público infantil.

Destaca-se a necessidade da democratização da ciência de maneira alegre e divertida (brincadeiras, modelagem, pintura, observação do céu) para o público infantil, ajudando-o a compreender alguns dos fenômenos de Ciências (Astronomia), especialmente na cidade de Manaus-AM - lócus desta pesquisa.

\section{DIVULGAÇÃO CIENTÍFICA PARA AS CRIANÇAS EM ESPAÇO NÃO FORMAIS}

A Divulgação Científica (DC) tem se destacado nas pesquisas do Ensino de Ciências, sendo uma tendência que adentra no campo da educação formal e não formal. No Brasil, segundo Nascimento e Junior (2010, p. 01): “Já é possível localizar nos eventos eixos temáticos especificamente voltados para a Divulgação Científica, bem como identificar artigos sobre as relações entre os diferentes meios utilizados para a divulgação formal e não formal da ciência”.

A DC tem cada vez mais destaque em eventos científicos, principalmente nesse momento da pandemia (causada pela Covid-19), mediante as lives e atividades online entre pares. Esse cenário veio ressaltar ainda mais a importância da valorização das pesquisas nesse campo de estudo, tanto em espaços formais, como não formais. 
Neste sentido, enfatiza-se a necessidade de desenvolver práticas de DC, desde a mais tenra idade, com propostas que propiciem os estudos das ciências e da pesquisa, através de visitas em museus, centros de ciências, Zoológicos, participação de feiras de ciências, utilizações de jornais, revistas, programas televisivos, sites e diversos meios de comunicação.

Em outras palavras, compreende-se que os espaços não formais "são o caminho mais imediato e abrangente de intensificar a divulgação científica para o grande público" (IVANISSEVICH, 2005, p. 14), tendo um potencial relevante para a disseminação de uma cultura científica, ou seja, requer seu início na infância.

Desse modo, observa-se que a expressão "Cultura Científica” se refere aos fenômenos ligados à ciência, tais como: Alfabetização Científica, Divulgação Científica e percepção/compreensão da ciência. Isto é, dá a ideia de que o processo envolve o desenvolvimento científico que considera a produção, a difusão entre pares e a dinâmica do ensino/educação (VOGT, 2003).

Nessa perspectiva, compreendemos que se faz necessário aguçar a curiosidade das crianças, despertando nelas o interesse pelas descobertas e a ampliação dos seus conceitos científicos, algo que, para Vygotsky (1987), relacionam-se às concepções construídas por elas em suas interrelações com elementos culturais - conceitos cotidianos - de forma que essas percepções sejam introduzidas no pensamento da criança, tal qual uma organização sistêmica. Pois, os conceitos cotidianos modificam os científicos.

Dessa maneira, a "transmissão de conceitos" prontos para as crianças é interpretado como algo que não tenha uma relação com o seu cotidiano e não seja (re)construído através de seus saberes. Em outras palavras, refere-se a algo que pode vir a ser uma repetição mecânica, conteudista, com termos vazios de significados (VYGOTSKY, 1987).

Nesse cenário, as crianças são imersas em um ambiente com uma variedade de estímulos (internet, aparelhos eletrônicos e digitais) e sua atenção é tomada por eles. A esse respeito, Selbach et al (2010) desafiam o professor a utilizar metodologias e técnicas criativas, em locais diferenciados, com recursos que estimule o interesse das crianças pelas temáticas desenvolvidas durante o seu processo educativo.

Um dos caminhos a serem seguidos perpassam pela utilização de espaços educativos não formais, ainda mais porque saem do limite da escola para um ambiente que faz parte ou não do dia a dia das crianças. Esses espaços podem ser categorizados em institucionalizados: museus, zoológicos, Jardins Botânicos, Institutos de Pesquisas entre outros; como também 
em: não institucionalizados, como, por exemplo: teatro, parque, praças, rua, dentre inúmeros espaços (JACOBUCCI, 2008).

Os ambientes que ultrapassam os espaços tradicionais de ensino podem proporcionar experiências significativas para os sujeitos envolvidos, pois, além de serem diferenciadas das atividades proporcionadas nas instituições de ensino, também favorecem a conexão, relação e interação com todos os elementos encontrados nesses ambientes.

A esse respeito, Lorenzetti e Delizoicov (2001, p. 7) definem os espaços não formais em seus estudos, a seguir descrito:

[...] museus, zoológicos, parques, fábricas, [...], além daqueles formais, tais como bibliotecas escolares e públicas, constituem fontes que podem promover uma ampliação do conhecimento dos educandos. As atividades pedagógicas desenvolvidas que se apoiam nestes espaços, em aulas práticas, saídas a campo, feiras de ciências, por exemplo, poderão propiciar uma aprendizagem significativa contribuindo para um ganho cognitivo.

Esse contexto corrobora com o que é descrito por Cunha (2009) dentro desses locais, isto é, as atividades educativas favorecem a observação e a problematização dos fenômenos de uma forma mais concreta, além de propiciarem um ambiente alternativo de ensinoaprendizagem, cuja contribuição para o desenvolvimento de uma aprendizagem está relacionada ao cotidiano da criança.

Para Andrade (2018), a Divulgação Científica (DC) é importante para a formação de conceitos, sendo um poderoso meio para a divulgação das Ciências que, associado às atividades relacionadas aos filmes/desenhos animados, meios de comunicações e espaços não formais, podem proporcionar na criança compreensões sobre as Ciências.

[...] as crianças trazem para escola questionamentos científicos (as estrelas são redondas? O sol é uma estrela?) que podem ser explorados. Para ajudá-las a esclarecer suas dúvidas por respostas sobre o mundo, os fenômenos da natureza e da sociedade, o professor pode utilizar como recurso didático os vários veículos de DC (ANDRADE, 2018, p. 103).

Considera-se assim que os espaços não formais favorecem a realização da divulgação científica para as crianças, pois, esses ambientes interagem de maneira direta e indireta com os sujeitos que têm esse contato. Em outras palavras, compreendemos que possuem potenciais para o desenvolvimento de práticas educativas que despertam o interesse das crianças e 
agucem as suas curiosidades, como evidencia-se nesta pesquisa, a partir da atividade "De olho no céu", que trata de uma temática que envolvem "Crianças e Infâncias"”.

\section{METODOLOGIA}

$\mathrm{O}$ artigo possui uma abordagem qualitativa, porque permite responder questões oriundas do processo de reflexão sobre fenômenos que não podem ser reduzidos a variáveis (MINAYO, 2011). Nesse sentido, busca-se apresentar uma experiência realizada antes da pandemia causada pela disseminação da Covid-19 (doença causada pelo Sars-CoV-2), que teve seu início de proliferação em Manaus, no mês de março de 2019. A partir disso, a exposição teve como intitulação: "De olho no céu”, localizado no largo São Sebastião, Manaus - AM, em parceria com o Museu Amazônico, órgão suplementar da Universidade Federal do Amazonas (UFAM).

As ações foram realizadas na semana da criança, organizada pelo Museu Amazônico, como pode-se observar na programação da figura 1, seguindo as atividades organizadas em três espaços distintos (Quadro 1).

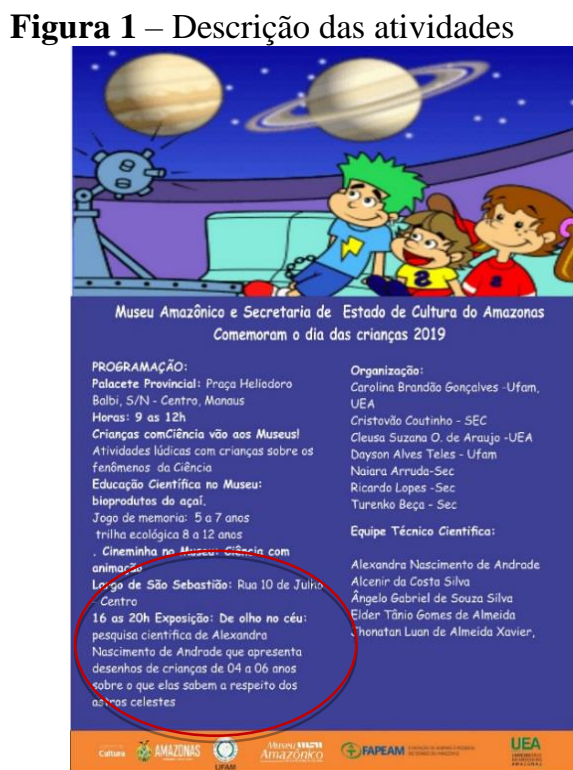

Fonte: https://edoc.ufam.edu.br/bitstream/123456789/2481/1/MUSEU-AMAZONICO.jpeg

A Exposição "De olho no céu”, realizada no Largo São Sebastião, Manaus - AM, em

1 “Crianças e Infâncias” está no plural por se tratar de um olhar embasado na Sociologia da infância 
parceria com o Museu Amazônico, órgão suplementar da Universidade Federal do Amazonas (UFAM), tiveram os seguintes momentos descritos no Quadro 1.

\begin{tabular}{|l|l|}
\hline \multicolumn{1}{|c|}{ ESPAÇO } & \multicolumn{1}{|c|}{ Quadro 1 - Descrição das atividades } \\
\hline Desenhos "De olho no céu". & $\begin{array}{l}\text { Exposição de desenhos de crianças sobre o Sistema Solar e algumas } \\
\text { de suas curiosidades. }\end{array}$ \\
\hline $\begin{array}{l}\text { Observação de uma Maquete do } \\
\text { Sistema Solar (Figura 02). }\end{array}$ & $\begin{array}{l}\text { Exposição de uma maquete do Sistema solar, demonstrando a } \\
\text { diferença de tamanho dos planetas, conforme uma escala } \\
\text { demonstrativa. }\end{array}$ \\
\hline $\begin{array}{l}\text { Pintando e modelando os } \\
\text { planetas do Sistema Solar } \\
\text { (Figura 02). }\end{array}$ & $\begin{array}{l}\text { Atividade para as crianças modelarem os planetas do sistema solar, } \\
\text { mediante a uma escala de um sol com um raio de 3m. } \\
\text { Desenho e pintura livre dos planetas do sistema solar. }\end{array}$ \\
\hline $\begin{array}{l}\text { Observação do céu. } \\
\text { Observação do céu noturno com um telescópio. }\end{array}$ \\
\hline
\end{tabular}
Fonte: Autoras, 2021.

O objetivo proposto da atividade foi analisar o interesse das crianças por temas de Astronomia, identificando seus conhecimentos prévios e curiosidades sobre as temáticas que envolviam os corpos celestes, salientando assim a importância dos museus para a democratização da Ciência, desde o público infantil.

Desse modo, o enfoque desta investigação é descritivo, uma vez que sugere reflexões a partir de ações vividas, sendo relevante a comunicação à comunidade científica (FONSECA, 2010). Assim sendo, durante o trabalho, registramos quais as indagações feitas pelas crianças sobre os corpos celestes.

Para o tratamento dos dados, utilizou-se a análise do conteúdo que esclarece como pontuar, criticamente, e avaliar os conteúdos de uma pesquisa, recomendando uma "descrição objetiva e sistemática", seja nos aspectos de organização, seja na transcrição, como também no levantamento de categorias (BARDIN, 2016).

A técnica de gerenciamento de dados partiu-se da observação participante, mediante gravações, filmagens e fotografias, por meio de smartphones. As transcrições das narrativas dos participantes possibilitaram a construção de categorias de análise para compreender as perspectivas de descoberta e reconstrução do conhecimento científico sobre Astronomia.

\section{ANÁLISE E RESULTADOS}

Na Exposição "De olho no céu”, realizada no largo São Sebastião, Manaus-AM, em parceria com o Museu Amazônico, órgão suplementar da Universidade Federal do Amazonas 
(UFAM), foi evidenciado o interesse das crianças por temas de Astronomia. Ali, identificouse nas narrativas e conversas gravadas de 34 crianças, os conhecimentos prévios e curiosidades infantis sobre as temáticas que envolveram os corpos celestes. Nesse cenário, elencamos em cinco categorias o seguinte: 4.1 Curiosidades; 4.2 Reações (subcategorias: reação de explicação sobre o que conheciam, reação de espanto e reação de descoberta); 4.3 Desejo de conhecer os corpos celestes; 4.4 Conhecimento apresentado; e, 4.5 A importância de atividades de democratização à Ciência em espaços não formais.

\subsection{Curiosidades}

A primeira categoria refere-se às curiosidades que as crianças apresentaram em suas narrativas, de modo que reforçassem o interesse delas por assuntos que envolviam os corpos celestes.

Ao descrever as observações e os fatos (no quadro 2) no decorrer da realização das atividades, destaca-se a curiosidade das crianças sobre assuntos que envolvem os corpos celestes, corroborando com a premissa de Andrade (2020) quando enfatiza a importância de se ouvir as crianças quanto as suas curiosidades sobre o que existe no céu.

Quadro 2 - Observações e fatos

\begin{tabular}{|l|l|}
\hline \multicolumn{1}{|c|}{ OBSERVAÇÕES } & \multicolumn{1}{|c|}{ FATOS } \\
\hline $\begin{array}{l}\text { O Quantitativo de crianças na } \\
\text { observação dos Desenhos "De } \\
\text { olho no céu" e da maquete do } \\
\text { Sistema Solar. }\end{array}$ & $\begin{array}{l}\text { As crianças ao chegarem no largo são Sebastião começaram a chegar no } \\
\text { local onde estavam os desenhos e a maquete, apontar os planetas que já } \\
\text { conheciam e fazer perguntas sobre os nomes daqueles que tinham } \\
\text { dúvidas. }\end{array}$ \\
\hline $\begin{array}{l}\text { Observação de uma Maquete do } \\
\text { Sistema Solar. }\end{array}$ & $\begin{array}{l}\text { A participação nas atividades e perguntas sobre os planetas e os } \\
\text { tamanhos que elas observavam na maquete. } \\
\text { A surpresa e curiosidade sobre porque tinham vários "Saturnos". }\end{array}$ \\
\hline Observação do céu. & $\begin{array}{l}\text { Muitas crianças pediram aos pais para esperar anoitecer, com intuito de } \\
\text { observar o céu no telescópio. } \\
\text { A fila de crianças para a observação do céu. }\end{array}$ \\
\hline
\end{tabular}

Fonte: Autoras, 2021.

A Exposição "De olho no céu", realizada no largo São Sebastião, Manaus-AM, possibilitou estimular as indagações das crianças para a exploração de temáticas de Astronomia, o que para Curval e Peixoto (2015) significa o despertar da curiosidade infantil, devido a observação diária delas, ainda que, muitas vezes, seja algo que pareça estar fora do seu alcance ou de sua compreensão. 


\subsection{Reações}

$\mathrm{Na}$ segunda categoria evidencia-se as reações das crianças de forma espontânea e livre. Percebe-se que os risos, gritos, espantos e gargalhadas fazem parte das interações, dos olhares, das perguntas e das conversas delas sobre os assuntos relacionados ao sistema solar. Assim, percebeu-se que "mesmo as crianças não identificando o sol como uma estrela, nas falas delas, existe um potencial a ser investigado e divulgado sobre o sol, pois é um elemento presente em seu cotidiano" (ANDRADE, 2018, p. 65).

O público infantil que já havia estudado na escola sobre o Sistema Solar, ao modelar (com massinhas) e desenhar os planetas (Figura 02), diziam os respectivos nomes deles às crianças menores - reação de explicação sobre o que conheciam (Subcategoria).

Outra ação interessante foi a reação de espanto (Subcategoria) de uma criança, isto é, ao ouvir que o sol era uma estrela, para ela, "o sol era o sol-aparecia no dia, as estrelas apareciam somente à noite" (C13).

Compreendemos desse contexto que para o estudo algo que visto diretamente pelas crianças, ou seja: fazem com que os espaços não formais de ensino possam propiciar “"[...] aos alunos atividades de aprendizagem, onde relacionam os conteúdos teóricos com a realidade numa perspectiva interdisciplinar e, auxiliando-os a compreenderem melhor a realidade" (REIS et al, 2019, p. 26).

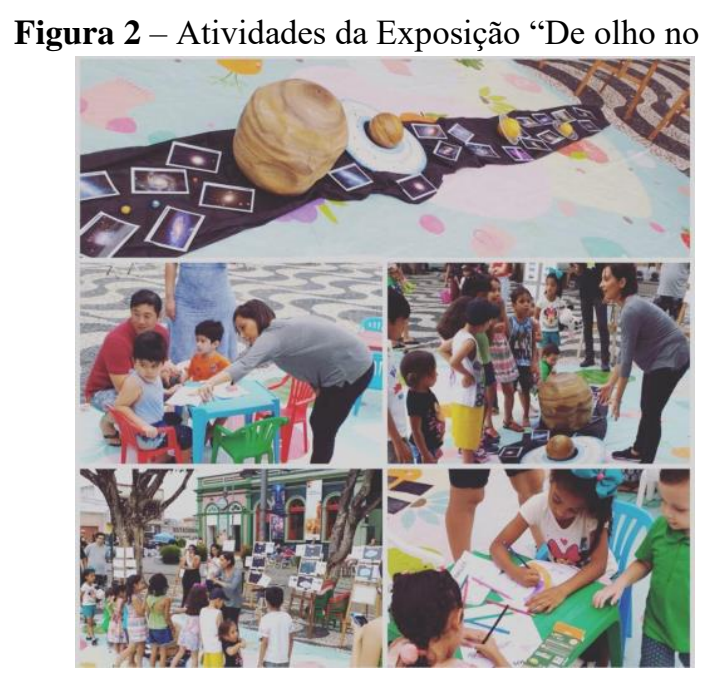

Fonte: Autoras, 2021.

Outro fato que chamou a atenção foi a reação de descoberta (Subcategoria) tanto das crianças, quanto de alguns adultos presentes sobre os planetas do Sistema Solar, isto é, o fato 
de que possuem anéis (Júpiter, Saturno, Urano, Netuno), como também a diferença dos tamanhos de cada planeta, demonstrado na maquete (Figura 2).

Entendemos que as atividades propostas conseguiram possibilitar para todos os adultos ou crianças presentes a construção de novos conhecimentos/descobertas de algumas curiosidades sobre Astronomia. Nesse contexto, a afirmativa corrobora com os princípios proposto por Natal e Alvin (2018) ao ressaltarem que, mediante a DC, é possível comunicar o conhecimento científico, no sentido de torná-lo comum, isto é, acessível e compreensível não apenas ao meio acadêmico, todavia ao mais diversos público.

\subsection{Desejo de conhecer os corpos celestes}

$\mathrm{Na}$ terceira categoria - Desejo de conhecer os corpos celestes - as crianças que não sabiam os nomes dos planetas pegavam os objetos representativos (Fichas ilustradas com os nomes dos planetas e curiosidades sobre eles) deles para perguntar os seus nomes, quem era o maior etc.

Nesse cenário, observou-se que o público infantil que passeava com seus pais, paravam na exposição e começava a perguntar sobre o que estava sendo exposto. Conforme o Quadro 02, pode-se destacar as crianças que fizeram seus pais esperarem a chegada do anoitecer para observarem os astros, com o telescópio. Quando iniciou a observação, a fila foi aumentando tanto da parte das crianças como dos adultos.

O fato de as crianças esperarem para a observação destaca o desejo de conhecerem os astros, de um lado; de outro, revela nesse tipo de pratica a importância de propiciar atividades sobre essa temática ao público infantil. A esse respeito, Curval e Peixoto (2008) afirmam que é nessa fase que se deve estimular a criança para o contato com o mundo físico, despertando nelas um olhar atento e com significado em tudo que observam.

Para as Orientações Curriculares Educação Pré-Escolar - OCEPE (MINISTÉRO DA EDUCAÇÃO, 1997), é relevante a aprendizagem das Ciências, nos primeiros anos, devendo ser estimulada mediante a exploração de fenômenos e situações presentes no seu cotidiano, como os assuntos e curiosidades da Astronomia. 


\subsection{Conhecimento apresentado}

$\mathrm{Na}$ figura 3 foram organizadas as palavras com maior frequência e referentes às falas do público infantil, destacando os conhecimentos apresentados pelo público que visitou a exposição "De olho no céu”, a saber.

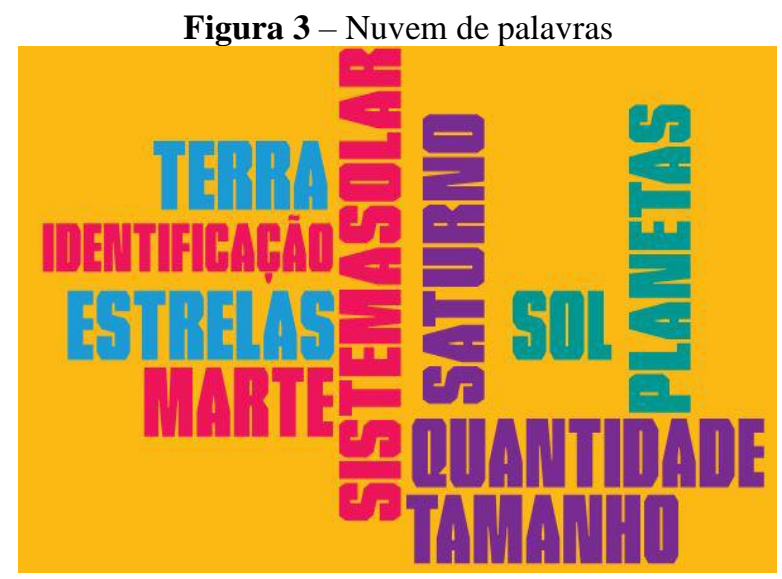

Fonte: Autoras, 2021

As crianças, ao observarem os desenhos da Exposição "De olho no céu” (Figura 2), a maquete no chão (Figura 3), identificavam os seguintes planetas: Terra, Marte e Saturno. Ao tentar descobrir o porquê somente esses planetas estão em maior constância nas falas das crianças, foi constatado que a relação com a imagem do planeta Terra e de Marte, presente em filmes, livros, estudos nas escolas e em alguns desenhos animados, bem como o planeta Saturno ser colocado nos livros didáticos de maneira errônea (vulgarização da Ciência) como o único planeta a ter anéis.

Algumas crianças relacionaram o planeta Marte a sua cor vermelha, presente no protótipo da maquete. Em alguns desenhos da exposição, por terem ouvido que ele é o planeta de tal cor mencionada. Saturno, por sua vez, foi o planeta mais reconhecido devido os seus anéis, sendo confundido também com Urano e Netuno, devido a maquete da exposição representar esses planetas com a presença dos anéis.

Por meio de atividades de demonstrações ilustrativas icônicas, as quais envolvem o planetário e exposições, as crianças tiveram a experiência e ampliaram a formação de conceitos de Astronomia, ainda mais ao perceberem as características dos astros, com suas respectivas dimensões, relativamente próximas da realidade (ANDRADE, 2020), 
favorecendo uma visão coerente de Ciências, que muitas vezes é vulgarizada pelos livros didáticos nas escolas, principalmente no ensino das crianças.

Sendo assim, Kallery (2010) salientada a importância da abordagem dos fenômenos físicos na educação pré-escolar, inclusive assuntos relacionados aos fenômenos ligados à Astronomia, nos quais se defende uma abordagem informal.

\subsection{A importância de atividades de democratização à Ciência em espaços não formais}

$\mathrm{Na}$ categoria 5, descrevemos a fala da pedagoga do Museu Amazônico, atual diretora da Divisão de Difusão Cultural e organizadora geral do ocorrido, na entrevista dada ao site da UFAM (https://www.ufam.edu.br/ultimos-eventos/640-museu-amazonicoinclui-ciencia-na-programacao-do-dia-das-criancas-dia-12.html), para divulgação do evento:

[...] é necessário democratizar a Ciência, desde a infância, de modo a tornar o conhecimento científico familiar e atraente às crianças, uma vez que a Ciência faz. parte do patrimônio cultural produzido pela sociedade, no qual elas também fazem parte, não só recebendo passivamente, mas também produzindo cultura [...] uma das estratégias pode começar pelos Museus, tornando-os espaços que acolham com alegria e diversão esse público, atuem de modo dinâmico e interativo com os pequenos de maneira a ajudá-los a compreender os fenômenos da Ciência, valorizálos e poderem auxiliá-los a agir no mundo (PEDAGOGA CBG, 2019).

Nesse sentido, aduz a relevância dos espaços não formais, como, por exemplo: museus, praças, entre outros, desenvolverem atividades sobre a Ciência ao público mais diversificado, com o intuito de democratização científica, bem como a Exposição "De olho no céu" pode oferecer uma experiência sobre a Astronomia para o público infantil de diferentes classes e nacionalidades, pois, o Largo São Sebastião é um local público situado no centro da cidade de Manaus, frequentado por turistas, pessoas de classe alta e média, assim como imigrantes haitianos e venezuelanos que moram nas redondezas.

Conforme Mendes (2006), a Divulgação Científica participa da educação científica porque influencia diretamente na construção e na manutenção de uma sociedade democrática. Ademais, para Andrade (2018), a DC é importante também para o processo educacional, a ampliação/complementação do ensino formal e o desenvolvimento cultural científico. 


\section{ALGUMAS CONSIDERAÇÕES}

Com intuito de analisar o interesse das crianças por temas de Astronomia, identificando seus conhecimentos prévios e curiosidades sobre as temáticas que envolvem os corpos celestes, evidenciamos, mediante a "Exposição De olho no céu", a relevância de abordar essa temática desde a mais tenra idade, bem como de ressaltar a importância dos museus e exposições científicas para a democratização da Ciência, desde o público infantil.

Através das categorias de análise deste estudo, constatou-se algumas curiosidades que as crianças têm sobre os corpos celestes, suas reações ao se depararem com novos conhecimentos, como: Quantos planetas do sistema solar tem anéis? O sol é uma estrela?

Observou-se ainda o desejo das crianças em conhecer os corpos celestes (observar planetas e estrelas) através do telescópio, bem como destacarem seus conhecimentos apresentados (sobre os nomes dos planetas e algumas de suas características).

Em outras palavras, percebeu-se a importância de atividades de democratização à Ciência em espaços não formais, assim como de parcerias de museus e centros acadêmicos em atividades expositivas em praças públicas.

De acordo com os resultados, observou-se que as crianças demonstraram interesse em participar das atividades, dialogando entre elas e com as pesquisadoras, ou seja, respondendo perguntas sobre os planetas e aprendendo algumas curiosidades (os 4 planetas gasosos do sistema solar têm anéis - não só o Saturno).

A democratização da Ciência, mediante a exposição "De olho no céu" aconteceu de maneira alegre e divertida (brincadeiras, modelagem, pintura, observação do céu) para o público infantil, ajudando-os a compreender alguns dos fenômenos da Ciência. Logo, teve o intuito de aguçar as curiosidades delas e auxiliá-las a agir no mundo de maneira crítica e participativa.

O estudo possibilitou mostrar uma prática de Divulgação científica realizada em um espaço não formal (Largo São Sebastião) com crianças de várias nacionalidades, idades e classes sociais, demonstrando assim a necessidade de mais práticas que pudessem envolver temáticas científicas para o público infantil, especialmente na cidade de Manaus-AM.

Esperamos, a partir destas discussões, ter contribuído ao campo de discussão desse tema, com recomendações que possam ajudar na organização de propostas de Divulgação Científica para as crianças, sobretudo em espaços abertos, e atendam as mais diversas 
realidades infantis, tendo como sugestões a organização periódicas de atividades que promovam assuntos que envolvam a Ciência em espaços não formais.

\section{REFERÊNCIAS}

ANDRADE, A. N. As potencialidades do uso dos desenhos das crianças da educação infantil para a Divulgação Científica. Dissertação - PGSS - Educação em Ciências na Amazônia (Mestrado). Universidade do Estado do Amazonas. Manaus, 2018. Disponível em: http://177.66.14.82/handle/riuea/3293. Acesso em: 20 de maio de 2021.

ANDRADE, A. N. Desenho infantil: uma experiência com, por e para os curumins e cunhantãs. $1^{\text {a }}$ ed. Curitiba: Appris, 2020.

BARDIN, L. Análise de conteúdo. São Paulo: Edições 70, 2016.

FONSECA, Luiz Almir Menezes. Metodologia científica ao alcance de todos. Manaus: Editora Valer, 2010.

KALLERY, M. Astronomical Concepts and Events Awareness for Young Children. International Journal of Science Education, v. 01, p. 1-29, 2010. DOI: $10.1080 / 09500690903469082$.

MENDES, M. F. A. Uma perspectiva histórica da divulgação científica: a atuação do cientista-divulgador José Reis (1948-1958). Tese. (Doutorado). Pós-Graduação em História das Ciências e da Saúde da Casa de Oswaldo Cruz- FIOCRUZ. Rio de Janeiro, 2006.

MINAYO, Maria Cecília de Souza. Pesquisa social: teoria, método e criatividade. $25^{\mathrm{a}}$ ed. Petrópolis, RJ: Vozes, 2011.

Ministério da Educação. Orientações Curriculares para a Educação Pré-Escolar. Lisboa: ME, $1997 . \quad$ Disponível em: https://www.dge.mec.pt/sites/default/files/Basico/orientacoes_curriculares_pre_escolar.pdf.

Acesso em: 20 de maio de 2021.

NATAL, C. B.; ALVIM, M. H. A divulgação científica e a inclusão social. Revista do Edicc, v. 5, n. 1, p. 76-86, 2018. ISSN: 2317-3815. Disponível em: https://revistas.iel.unicamp.br/index.php/edicc/article/view/5964/7309. Acesso em: 22 de maio de 2021.

PEIXOTO, A. A criança e o conhecimento do mundo: atividades laboratoriais em ciências físicas. Penafiel: Editorial Novembro, 2008.

REIS, E. F. dos; SOUSA, M. F. da C.; ALVES, D. dos S.; PINHO, M. I. M.; RIZATTI, I. M. Espaço não formais de educação na prática pedagógica de professores de ciências. REAMEC - Revista da Rede Amazônica de Educação em Ciências e Matemática, v. 7, n. 3, 2019. p. 23-36 ISSN: 
https://periodicoscientificos.ufmt.br/ojs/index.php/reamec/article/view/8265/pdf . Acesso em: 22 de maio de 2021. DOI: 10.26571/reamec.v7i3.8265.

SELBACH, S. et al. Matemática e didática: como bem ensinar. Petrópolis: Vozes, 2010

VOGT, C. A. Espiral da cultura científica. Com Ciência-Cultura Científica [online], 2003. Disponível em: http://www.comciencia.br/reportagens/cultura/cultura01.shtml.

Acessado em: 21 de maio de 2021.

VYGOTSKY, L. S. O desenvolvimento dos conceitos científicos na infância. In: CAMARGO, J. L. Pensamento e linguagem. $2^{a}$ ed. São Paulo: Martins Fontes, 1987.

\section{Apêndice 1}

\section{AGRADECIMENTOS}

Agradecemos as instituições que favoreceram o provimento da pesquisa como Universidade do Estado do Amazonas - UEA, Universidade Federam do Amazonas e ao Museu Amazônico do Amazonas. Aos professores e estudantes que se movimentaram para prover e participar de todos os processos da pesquisa científica.

\section{FINANCIAMENTO}

Financiado pelo(s) próprio(s) autor(es)

\section{CONTRIBUIÇÕES DE AUTORIA}

Resumo/Abstract/Resumen: Adana Teixeira Gonzaga e Alexandra Nascimento de Andrade Introdução: Adana Teixeira Gonzaga

Referencial teórico: Adana Teixeira Gonzaga

Análise de dados: Alexandra Nascimento de Andrade

Discussão dos resultados: Adana Teixeira Gonzaga e Alexandra Nascimento de Andrade

Conclusão e considerações finais: Adana Teixeira Gonzaga e Alexandra Nascimento de Andrade

Referências: Alexandra Nascimento de Andrade

Revisão do manuscrito: Alexandre da Silva Santos

Aprovação da versão final publicada: Adana Teixeira Gonzaga e Alexandra Nascimento de Andrade

\section{CONFLITOS DE INTERESSE}

Os autores declararam não haver nenhum conflito de interesse de ordem pessoal, comercial, acadêmico, político e financeiro referente a este manuscrito.

\section{DISPONIBILIDADE DE DADOS DE PESQUISA}

Os autores declaram que deixam disponíveis as informações contidas nesse manuscrito para publicações em revistas ou até mesmo que possam ser utilizadas em novas pesquisas no campo educacional

\section{CONSENTIMENTO DE USO DE IMAGEM}

Não se aplica

\section{APROVAÇÃO DE COMITÊ DE ÉTICA EM PESQUISA \\ Não se aplica}

\section{COMO CITAR - ABNT}

ANDRADE, Alexandra Nascimento de; GONZAGA, Adana Teixeira; GONÇALVES, Carolina Brandão. De olho no céu: divulgação científica para com as crianças em espaço não formal manauara. REAMEC - Rede Amazônica de Educação em Ciências e Matemática. Cuiabá, v. 9, n. 3, e21074, set./dez., 2021. https://doi.org/10.26571/reamec.v9i3.12684 


\section{COMO CITAR - APA}

Andrade, A. N. De, gonzaga, A. T., Gonçalves, C. B. (2021). De olho no céu: divulgação científica para com as crianças em espaço não formal manauara. REAMEC - Rede Amazônica de Educação em Ciências e Matemática, 9(3), e21074. https://doi.org/10.26571/reamec.v9i3.12684

\section{LICENÇA DE USO}

Licenciado sob a Licença Creative Commons Attribution-NonCommercial 4.0 International (CC BY-NC 4.0). Esta licença permite compartilhar, copiar, redistribuir o manuscrito em qualquer meio ou formato. Além disso, permite adaptar, remixar, transformar e construir sobre o material, desde que seja atribuído o devido crédito de autoria e publicação inicial neste periódico.

\section{DIREITOS AUTORAIS}

Os direitos autorais são mantidos pelos autores, os quais concedem à Revista REAMEC - Rede Amazônica de Educação em Ciências e Matemática - os direitos exclusivos de primeira publicação. Os autores não serão remunerados pela publicação de trabalhos neste periódico. Os autores têm autorização para assumir contratos adicionais separadamente, para distribuição não exclusiva da versão do trabalho publicada neste periódico (ex.: publicar em repositório institucional, em site pessoal, publicar uma tradução, ou como capítulo de livro), com reconhecimento de autoria e publicação inicial neste periódico. Os editores da Revista têm o direito de proceder a ajustes textuais e de adequação às normas da publicação.

\section{PUBLISHER}

Universidade Federal de Mato Grosso. Programa de Pós-graduação em Educação em Ciências e Matemática (PPGECEM) da Rede Amazônica de Educação em Ciências e Matemática (REAMEC). Publicação no Portal de Periódicos UFMT. As ideias expressadas neste artigo são de responsabilidade de seus autores, não representando, necessariamente, a opinião dos editores ou da referida universidade.

\section{EDITOR}

Dailson Evangelista Costa (D) 9

\section{HISTÓRICO}

Submetido: 28 de junho de 2021.

Aprovado: 27 de agosto de 2021.

Publicado: 17 de setembro de 2021. 